\title{
Down-regulation of S100A9 inhibits osteosarcoma cell growth through inactivating MAPK and NF-KB signaling pathways
}

Si Cheng ${ }^{1}$, Xi Zhang ${ }^{2}$, Ning Huang ${ }^{3,4}$, Quanhe Qiu ${ }^{1}$, Ying Jin ${ }^{5}$ and Dianming Jiang ${ }^{{ }^{*}}$

\begin{abstract}
Background: Osteosarcoma (OS) is well-known for poor prognosis due to its high incidence of proliferation and metastasis. Researches have provided valuable insights into the tumorigenesis of S100A9 in some cancers. We aimed to understand the expression level, functions and mechanisms of S100A9 in human osteosarcoma for the first time.

Methods: The expression of S100A9 protein was detected in 120 human osteosarcoma tissues and 40 normal human bone tissues using tissue microarrays analysis. The knockdown of S100A9 induced by RNA interference (RNAi) method in three osteosarcoma cell lines (U2OS, 143B, MG63) was applied to analyze the effects of S100A9 on cell proliferation, cell cycle distribution, migration, invasion and xenotransplanted tumors. Moreover, MAPK-ERK1/2, MAPK-p38, NF-kB-p65, NF-kB-p50, p21, p27, CDK2 and CDK4 were tested.

Results: The expression of S100A9 was increased in human osteosarcoma issues and was positively correlated with clinical classification and survival rate. Down-regulation of S100A9 inhibited OS cellular proliferation, migration, invasion and cell cycle S phase in vitro and suppressed tumor formation in vivo with the reduction on PCNA and Ki67 proliferation index. Our data also demonstrated that knockdown of S100A9 repressed the protein levels of phospho-ERK1/2, phospho-p50, phospho-p65 except phospho-p38, and prompted up-regulation of p21 and p27 leading to inactivation of cyclin dependent kinase 2(CDK2) and cyclin dependent kinase 4(CDK4).
\end{abstract}

Conclusions: S100A9 might be a significant role for predicting osteosarcoma prognosis and down-regulation of S100A9 could be used as a potential target for gene therapy.

Keywords: S100A9, Osteosarcoma, Proliferation, Invasion, Tumorigenesis, MAPK, NF-kB

\section{Background}

Osteosarcoma (OS) is one of the predominant bone sarcomas [1] as well as the third most common primary malignant bone tumor happened in children and adolescents [2]. OS is commonly characterized by its aggressive growth, high rate of local recurrence, and poor long-term survival rates for the early frequent systemic metastases, particularly for the lung metastasis [3]. Currently, the 5-year survival rate for patients with local OS remains approximately $65-70 \%$ and for patients

\footnotetext{
*Correspondence: jdm571026@vip.163.com

${ }^{1}$ Department of Orthopaedics, The First Affiliated Hospital of Chongqing

Medical University, Chongqing, PR China

Full list of author information is available at the end of the article
}

with metastatic diseases merely remains $20 \%$. Over the past 15 years, only a slight improvement was made in terms of OS therapeutic effects [4]. The main clinical treatment for OS patients includes wide surgical removal of all detectable disease (including metastases) and pre- or post-operative chemotherapy [5]. However, current chemotherapies often result in systemic toxicities (hearing loss, anemia, abnormal bleeding, and kidney/liver damage) and chemoresistance $[6,7]$. Thus, the OS treatment requires the development of some new-targeted therapies. Predicting the possibilities of proliferation or metastases in the OS patients would offer more options for doctors to make a suitable therapeutic strategy. A few new biomarkers have been found, and these biomarkers 
can be considered as the targets for ensuring effectiveness of the OS treatment, contributing to a better clinical management for OS patients.

S100A9 (calgranulin B or MRP-14), known as damageassociated molecular pattern (DAMP) molecule, is secreted by myeloid cells upon activation [8]. The intracellular and extracellular functions of S100A9 include calcium sensing, activation of NADPH oxidase and arachidonic acid transport $[9,10]$, regulation of tubulin-dependent cytoskeletal rearrangements [11] and effecting on cell migration and adhesion [12]. S100A9 was found in inflammatory conditions as well $[13,14]$. The relation between inflammation and carcinogenesis has long been recognized [15]. Increasing evidences affirmed that S100A9 plays an important role in tumorigenesis. The up-regulation of S100A9 has been observed in colon, gastric, bladder, pancreatic, ovarian, breast thyroid, and skin cancers [16], while S100A9 is reduced in in esophageal squamous cell carcinoma [17].

Mitogen-activated protein kinase (MAPK) is an insulinmitogen activated protein (Ser/Thr) kinase [18]. It is associated with cellular growth, survival and migration through regulating the signals from cell-surface to the nucleus by phosphorylation [19]. NF- $\kappa \mathrm{B}$, a transcription factor-a cytoplasmic heterodimer or homodimer interacting with an inhibitory protein of the IkB family, plays a critical role in the promotion of tumorigenesis [20, 21]. Some articles have reported that the activation of MAPK and NF- $\mathrm{kB}$ signaling pathways were detected in tumor cells and these two signaling pathways could be significance directions for oncotherapy $[22,23]$.

In this study, we investigated the expression of S100A9 protein in human osteosarcoma clinical samples and analyzed relevant clinicopathological characteristics. The functions of S100A9 were further understood in OS cells. Our results demonstrated that the knockdown of S100A9 inhibited human OS cellular growth in vitro and in vivo. To the best of our knowledge, this is the first report stating that over-expression of S100A9 might be a prerequisite for development and progression in human osteosarcoma.

\section{Methods}

\section{Reagents}

Fetal bovine serum (FBS) and Dulbecco's modified Eagle's medium (DMEM) were purchased from Gibco (San Francisco, California, USA). Primary anti-bodies: rabbit anti-human S100A9 was bought from ABCAM (MA, USA). Rabbit anti-human total ERK1/2 MAPK, rabbit anti-human total p38 MAPK, rabbit anti-human total p50 NF- $\mathrm{kB}$, rabbit anti-human total p65 NF- $\mathrm{kB}$ and antibodies against phospho-ERK1/2 MAPK, phospho-p38 MAPK, phospho-p50 NF- $\mathrm{B}$, phospho-65 NF- $\mathrm{B}$ were bought from Cell Signaling Technology (Boston, Massachusetts, USA). Rabbit anti-human p21 and p27 were purchased from Anbo Biotechnology (San Francisco, California,
USA). Rabbit anti-human Ki67 nuclear antigen, mouse anti-human PCNA and mouse anti-human glyceraldehydes3-phosphate dehydrogenase (GAPDH) were purchased from Santa Cruz Biotechnology (San Francisco, California, USA). Horseradish peroxidase-conjugated goat anti-rabbit and goat anti-mouse secondary antibodies were purchased from Zhong Shan Golden Bridge Biotechnology (Beijing, China).

\section{Tumor samples}

A total of 120 osteosarcoma (OS) patients who came from the First Affiliated Hospitals of Chongqing Medical University, Second Affiliated Hospitals of Chongqing Medical University, Children's Hospital of Chongqing Medical University (Chongqing, China) and Tumour hospital of Guizhou (Guizhou, China) between 2005 and 2014 were enrolled in this study. All tumor biopsies were collected at the time of initial diagnosis prior to preoperative chemotherapy or radiotherapy, with informed consent from patients/guardians. The patients were divided into IA, IB, IIA, IIB and III grades according to the GTM staging system (G-Histologic Grade, T-Anatomic site, MMetastasis). This study was approved by the ethics committee of the First Affiliated Hospitals of Chongqing Medical University, Second Affiliated Hospitals of Chongqing Medical University, Children's Hospital of Chongqing Medical University (Chongqing, China) and Tumour hospital of Guizhou (Guizhou, China).

\section{Normal bone samples}

A total of 40 normal bone tissues that came from the First Affiliated Hospitals of Chongqing Medical University were enrolled with consent from patients/guardians between 2012 and 2014. This study was approved by the ethics committee of the First Affiliated Hospitals of Chongqing Medical University.

\section{Tissue microarrays}

Tissue microarrays (TMAs) were constructed from 120 paraffin blocks of tumor tissues and 40 normal bone tissues using a tissue array device (Beecher Instruments, Sun Prairie, WI).

\section{Immunohistochemistry (IHC)}

Antigen retrieval on the deparaffinized sections was performed by immersing the samples in $0.1 \mathrm{M}$ citrate buffer ( $\mathrm{pH}$ 6.0), boiling the sections in the microwave for $10 \mathrm{~min}$, and then allowing the sections to cool down to room temperature. Endogenous peroxidase activity was blocked by immersing the sections in methanol containing $3 \%$ hydrogen peroxide for $10 \mathrm{~min}$. After blocked in goat serum for $10 \mathrm{~min}$ at room temperature, the sections were incubated with the S100A9 antibody (1:50) overnight at $4{ }^{\circ} \mathrm{C}$. Then, the sections were incubated with 
the secondary antibody at $37{ }^{\circ} \mathrm{C}$ for $30 \mathrm{~min}$. Streptavidin conjugated peroxidase was added and kept for $10 \mathrm{~min}$ at room temperature. Diamino-benzidine substrate was added and kept for $5 \mathrm{~min}$ for visualizing. Immunohistochemical staining of S100A9 provided calculations of both percentage of positive cells and color intensity. The percentage of the positivity of staining was graded as "0"(negative), "1" $<10 \%)$, "2" (10-50\%), and "3"(>50\%). The intensity of staining was scored as "0" (absent), "1"(light yellow),"2"(yellowish brown) and "3"(brown). The staining index(SI) was used for assessing the expression of S100A9 protein. According to SI = proportion score $\times$ intensity score, 0 was categorized as negative(-); $1-2$ as low expression $(1+)$; $3-4$ as moderate expression(2+); 6 and 9 as high expression(3+).

\section{Cell culture}

Human OS lines MG63,143B and U2OS were recently purchased from Shanghai Life Academy of Sciences cell library (Shanghai, China). The OS lines (MG63,143B,2OS) were maintained in DMEM containing $10 \%$ fetal bovine serum, $100 \mathrm{U} / \mathrm{ml}$ penicillin and $100 \mathrm{U} / \mathrm{ml}$ streptomycin (Hyclone, Longan, Utah, USA) at $37{ }^{\circ} \mathrm{C}$ in $95 \%$ air/5 \% $\mathrm{CO}_{2}$ incubator.

\section{Knockdown of S100A9 in OS cells}

The siRNA sequences targeting S100A9 (AGGAGTT CATCATGCTGAT) were purchased from Invitrogen. OS cells in the exponential phase of growth were plated in six-well plates at $1 \times 10^{5}$ cells/well, incubated for $24 \mathrm{~h}$, then OS cells were transfected with $2 \mu \mathrm{g}$ of each plasmid for $6 \mathrm{~h}$ using Lipofectamine 2000 reagent (Invitrogen) and OPTI-MEM reduced serum medium (Invitrogen). The control OS cells were transfected with empty vectors. After $48 \mathrm{~h}$, the OS cells were incubated in a complete medium containing puromycin dihydrochloride (SigmaAldrich Co. St Louis, MO, USA; $2 \mu \mathrm{g} / \mathrm{ml}$ for 143B, MG63 and U2OS cell lines) for 2 weeks and subcloned the individual Puromycin-resistant cells in 6 well plates and expanded the cells into puromycin-resistant sublines.

\section{Measurement of cellular proliferation}

OS cells were seeded in 96-well plates at a density of 2000 cells/well. 10ul CCK-8(Beyotime Institute of Biotechnology, Beijing, China) was added to each well after $24 \mathrm{~h}, 48 \mathrm{~h}$, $72 \mathrm{~h}$ and $96 \mathrm{~h}$. The absorbance value was readable at $450 \mathrm{~nm}$ using an enzyme- labeled instrument.

\section{Flow cytometry analysis (FCM) of cell cycle distributions} $5 \times 10^{5}$ cells were harvested and fixed in $70 \%$ ice-cold ethanol at $4{ }^{\circ} \mathrm{C}$ overnight. The cells were incubated with $10 \mathrm{mg} / \mathrm{ml}$ RNase (Sigma, St Louis, Missouri, USA) and $50 \mu \mathrm{g} / \mathrm{ml}$ propidium iodide(Sigma) at $37{ }^{\circ} \mathrm{C}$ for $30 \mathrm{~min}$ in the dark. The cell cycle was analyzed by flow cytometer (BD Bioscience, Franklin Lakes, New Jersey, USA).

\section{Cell migration assay}

The migration of OS cells was assayed using the transwell chambers (BD Biosciences, CA, USA). The back of chambers was precoated with $5 \mathrm{mg} / \mathrm{ml}$ fibronectin $(50 \mu \mathrm{l})$. The layer of fibronectin should be dried for $1 \mathrm{~h}$. The OS cells $\left(1 \times 10^{5}\right)$ were put in the upper side of the 8 - $\mu \mathrm{m}$ pore size transwell chambers containing $0.1 \mathrm{ml}$ DMEM without serum and $500 \mu \mathrm{l}$ DMEM containing $10 \%$ FBS were added in 24-well-plates. After incubation for $12 \mathrm{~h}$, nonmigrated cells were removed by scraping. The cells were fixed with $4 \%$ paraformaldehyde for $30 \mathrm{~min}$ at $4{ }^{\circ} \mathrm{C}$ and stained with crystal violet for $20 \mathrm{~min}$ at room temperature. Then, a light inverted microscope (Nikon TE2000-U, Tokyo, Japan) was used to observe the cell migration.

\section{Cell invasion assay}

The cell invasion assay was also conducted using the transwell chambers. The back of chambers was precoated with $5 \mathrm{mg} / \mathrm{ml}$ fibronectin $(50 \mu \mathrm{l})$ and the upper compartment of the polycarbonate filter was coated with Matrigel $(5 \mathrm{mg} / \mathrm{ml}, 100 \mu \mathrm{l})$. The Matrigel matrix (BD Bioscience, USA) formed a continuous thin layer after drying for $1 \mathrm{~h}$ at $37^{\circ} \mathrm{C}$. The OS cells $\left(1 \times 10^{5}\right)$ were put in the upper part of chambers containing $0.1 \mathrm{ml}$ DMEM without serum and $500 \mu \mathrm{l}$ DMEM containing 10 \% FBS were added in 24well-plates. After incubation for $12 \mathrm{~h}$, non-invaded cells were removed by scraping. The cells were fixed with $4 \%$ paraformaldehyde for $30 \mathrm{~min}$ at $4{ }^{\circ} \mathrm{C}$ and stained with crystal violet for $20 \mathrm{~min}$ at room temperature. Then, a light inverted microscope (Nikon TE2000-U, Tokyo, Japan) was used to observe the cell invasion.

\section{Real-time quantitative PCR}

Total RNA was extracted using RNAiso Plus (Invitrogen, Carlsbad, California, USA) and the RNA samples were reverse-transcribed into cDNA using the Primescript RT reagent Kit (TaKaRa Biotechnology, Dalian, China). The primer sequence for S100A9 was 5'-TGGCTCCTCGGC TTTGACA GAGT-3'(forward) and 5'-TGGGTGCCCC AGCTTCACAGA-3'(reverse), and for GAPDH, 5' CTTTGGTATCGTGGAAGGACTC-3' (forward) and reverse 5' -GTAGAGGCAGGGATGATGTTCT-3'. Amplification conditions were as follows: incubation at $95{ }^{\circ} \mathrm{C}$ for $30 \mathrm{~s}$, followed by 40 cycles at $95{ }^{\circ} \mathrm{C}$ for $15 \mathrm{~s}$, and finally $60{ }^{\circ} \mathrm{C}$ for $45 \mathrm{~s}$. Data was normalized to GAPDH, and mRNA abundance was calculated using the $2^{-\triangle \Delta C T}$ method [24].

\section{Western blotting}

The cells were harvested and disrupted in lysis buffer (Beyotime Institute of Biotechnology, Beijing, China) 
containing phosphatase inhibitors and Phenylmethanesulfonyl fluoride (PMSF). An equal amount of each protein sample was separated by 8-12\% SDS-PAGE and transferred to polyvinylidene fluoride (PVDF) membranes. The membranes were blocked with $5 \%$ Bovine Serum Albumin (BSA) and incubated with primary antibodies for overnight at $4{ }^{\circ} \mathrm{C}$, including S100A9(1:800), total ERK1/2 MAPK(1:800), phospho-ERK1/2 MAPK(1:1000), total p38 MAPK (1:600), phospho-p38 MAPK(1:2000), total p65 NF-кB(1:800), phospho-p65 NF- $\mathrm{B}(1: 1000)$, total p50 NF-кB(1:500), phospho-p50 NF-кB (1:1000), p21(1:500) and $\mathrm{p} 27(1: 500)$. The membranes were rinsed $10 \mathrm{~min}$ for three times with TBST buffer,and incubated with horseradish peroxidase-conjugated secondary antibody (1:5000) for $1 \mathrm{~h}$ at $37^{\circ} \mathrm{C}$. Thenthe membranes were rinsed 3 more times with TBST buffer and quantified by the Quantity One 4.6 computer software (Bio-Rad, Hercules, California, USA).

\section{Enzyme activity assay}

The activity assay (Genmed Scientifics Inc, Shanghai, China) of ERK1/2, p38, p65, p50, CDK2 and CDK4 were used to measure the intracellular activity. $50 \mu \mathrm{g}$ of proteins samples were added into the 96-well-plate and the enzyme activities were determined using an enzymelabeled instrument at different wavelengths according to the manufacturer's instruction manual. The values are presented as the percentage (\%) of blank control.

\section{Xenograft tumor model}

The male nude mice (4 weeks) were obtained from the experimental animal center of Chongqing Medical University. All mice experiments were approved by experimental animal center of Chongqing Medical University. The OS cells were injected subcutaneously into the nude mice at a density of $5 \times 10^{6}$ cells per $100 \mathrm{ul}$ PBS. Tumor volume was measured at 7, 14, 21 and 28 days after injection. Mice were killed at 28 days, the xenograft tumors were dissected and embedded in paraffin for HE staining and IHC.

\section{Proliferation index in xenograft tumor}

IHC staining for the expression of Ki67(1:200) and Proliferating cell nuclear antigen (PCNA)(1:200) in xenograft tumor tissues were conducted. The proliferation index (Ki-67 and PCNA index) was measured (the percentage of positive cells from five randomly fields under a light microscopy at $\times 400$ magnification).

\section{Statistical analysis}

Statistical analyses were performed using SPSS 19.0. Statistical differences among groups were analyzed by ANOVA, $t$-test or chi-square test. The data was presented as mean \pm standard deviation (SD). All $p$ values were twosided with statistical significance of $p<0.05$.

\section{Results}

Over-expression of S100A9 in human OS tissues

In this study, we surveyed the expression of S100A9 in human OS tissues and normal human bone tissues, 120 specimens from OS patients and 40 normal human bone tissues were evaluated by tumor tissue microarrays. The histologic subtypes of all OS tissues were originated from osteoblast. Our tissue microarray analyses demonstrated that $95 \%$ of the OS specimens(114 of 120) was positively stained for S100A9 (Table 1). The distribution of S100A9 staining falls into three patterns: nuclear (17.5\%), cytoplasma (20.0\%), and both (57.5\%), but these distribution patterns failed to show a statistical significance on the survival $(p>0.05)$. There were no statistical significances in gender, age, sites according to the staining results (Table 1). Representative specimens with different OS GTM grades staining for S100A9 were shown in Fig. 1a. The data confirmed S100A9 was over-expression in OS and the high-grade tissues presented a higher expression level of S100A9 than lowgrade tissues according to the GTM staging system, but there was no statistical significance between Grade I and Grade II (Fig. 1b). The mRNA levels of S100A9 in all tissues were tested by real-time quantitative PCR (Fig. 1c), and the results agreed with the immunohistochemistry. Due to the low incidence of osteosarcoma, we only collected three fresh osteosarcoma tissues to test by western blot (Fig. 1d). We

Table 1 Correlation expression of S100A9 in osteosarcoma tissues and normal human bone tissues

\begin{tabular}{|c|c|c|c|c|c|}
\hline \multirow[t]{2}{*}{ Groups } & \multicolumn{4}{|l|}{ S100A9 } & \multirow[t]{2}{*}{$P$-value } \\
\hline & $3+(n)$ & $2+(n)$ & $1+(n)$ & $-(n)$ & \\
\hline \multicolumn{6}{|l|}{ Tissue } \\
\hline Normal tissue $(n=40)$ & 0 & 0 & 8 & 32 & \multirow[t]{2}{*}{0.000} \\
\hline Osteosarcoma tissue $(n=120)$ & 6 & 73 & 35 & 6 & \\
\hline \multicolumn{6}{|l|}{ Gender } \\
\hline Male $(n=71)$ & 4 & 46 & 17 & 4 & \multirow[t]{2}{*}{0.210} \\
\hline Female $(n=49)$ & 2 & 27 & 18 & 2 & \\
\hline \multicolumn{6}{|l|}{ Age } \\
\hline$>25(n=47)$ & 1 & 28 & 16 & 2 & \multirow[t]{2}{*}{0.378} \\
\hline$<25(n=73)$ & 5 & 45 & 19 & 4 & \\
\hline \multicolumn{6}{|l|}{ Site } \\
\hline Femur $(n=73)$ & 4 & 46 & 20 & 3 & \multirow[t]{3}{*}{0.086} \\
\hline Tibiofibula $(n=23)$ & 2 & 15 & 5 & 1 & \\
\hline Other sites $(n=24)$ & 0 & 12 & 10 & 2 & \\
\hline \multicolumn{6}{|l|}{ Clinical stage } \\
\hline $\mathrm{IA}(n=25)$ & 0 & 6 & 15 & 4 & \multirow[t]{5}{*}{0.000} \\
\hline $\mathrm{IB}(n=16)$ & 1 & 8 & 5 & 2 & \\
\hline$\| \mathrm{A}(n=38)$ & 2 & 30 & 6 & 0 & \\
\hline$\| \mathrm{B}(n=32)$ & 1 & 24 & 7 & 0 & \\
\hline\|\|$(n=9)$ & 2 & 5 & 2 & 0 & \\
\hline
\end{tabular}




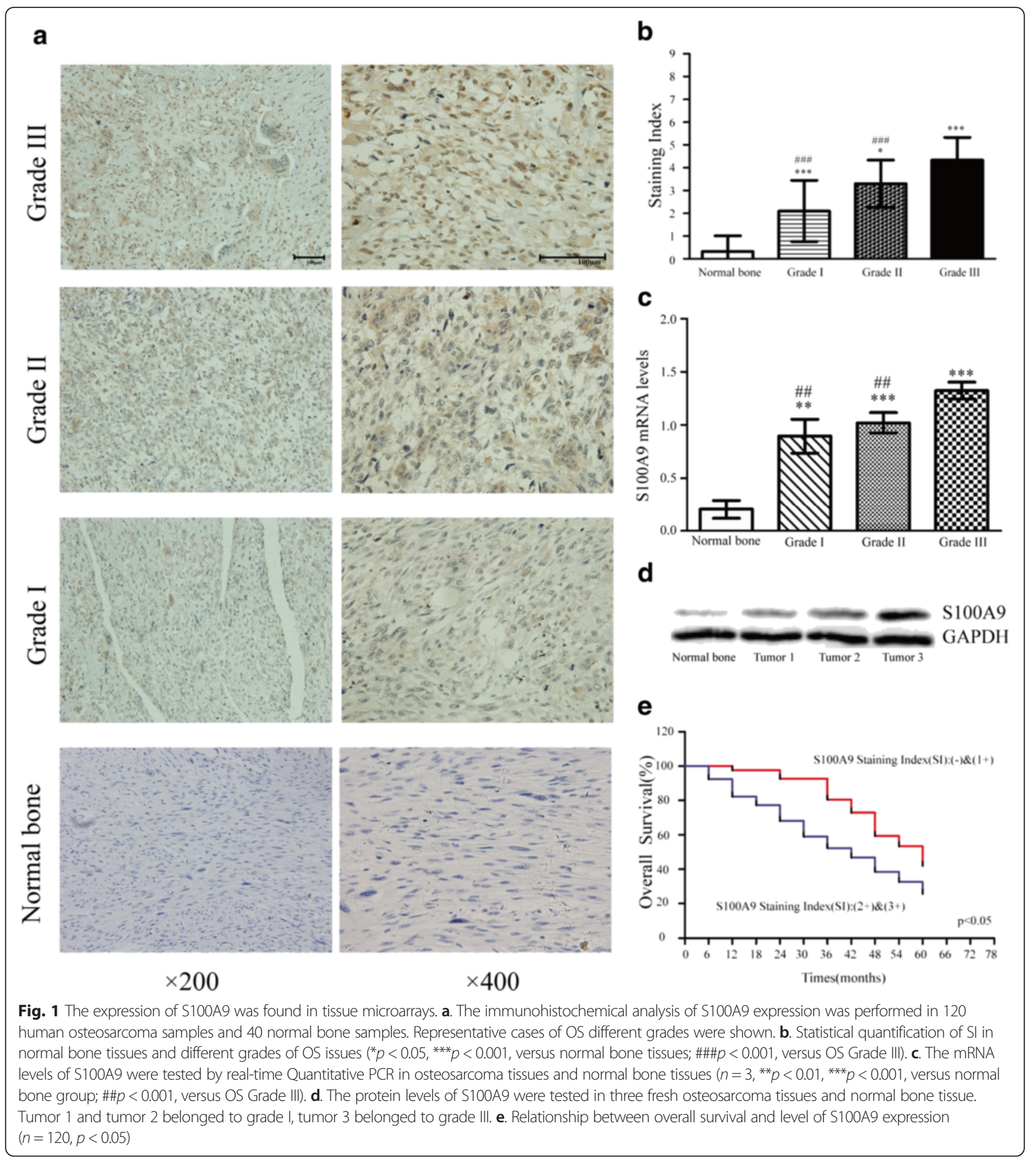

also assessed the survival ratios with respect of S100A9 staining index (SI) in all the human OS patients. 76 of 120 OS patients died at the time of the latest follow-up. We lost contact with 18 of the 120 patients during the follow-ups. Figure 1e demonstrated the survival curves for the human OS patients with S100A9 expression. The risk ratios for those patients with staining scores of moderate group and strong group were greater than those with staining scores of no staining group and weak group $(p<0.05)$.

\section{Knockdown of S100A9 contributes to reducing OS proliferation, migration and invasion in vitro}

Three OS cell lines (U2OS,MG63,143B) were transfected with S100A9-siRNA. Compared with cells transfected with 
empty vectors groups and blank control groups, the expression levels of S100A9 protein and mRNA were apparently reduced in the siRNA-S100A9 vectors groups according to the results of western blot (Fig. 2a) and real time PCR (Fig. 2b). CCk-8 assays demonstrated that down-regulation of S100A9 reduced the proliferation of the three OS cell lines in 1, 2, 3 and 4 days (Fig. 2c). Flow cytometric analysis was used for searching the reason why down-regulation of S100A9 could inhibit OS proliferation. The percentage of G0/G1 and S phase cells in each group

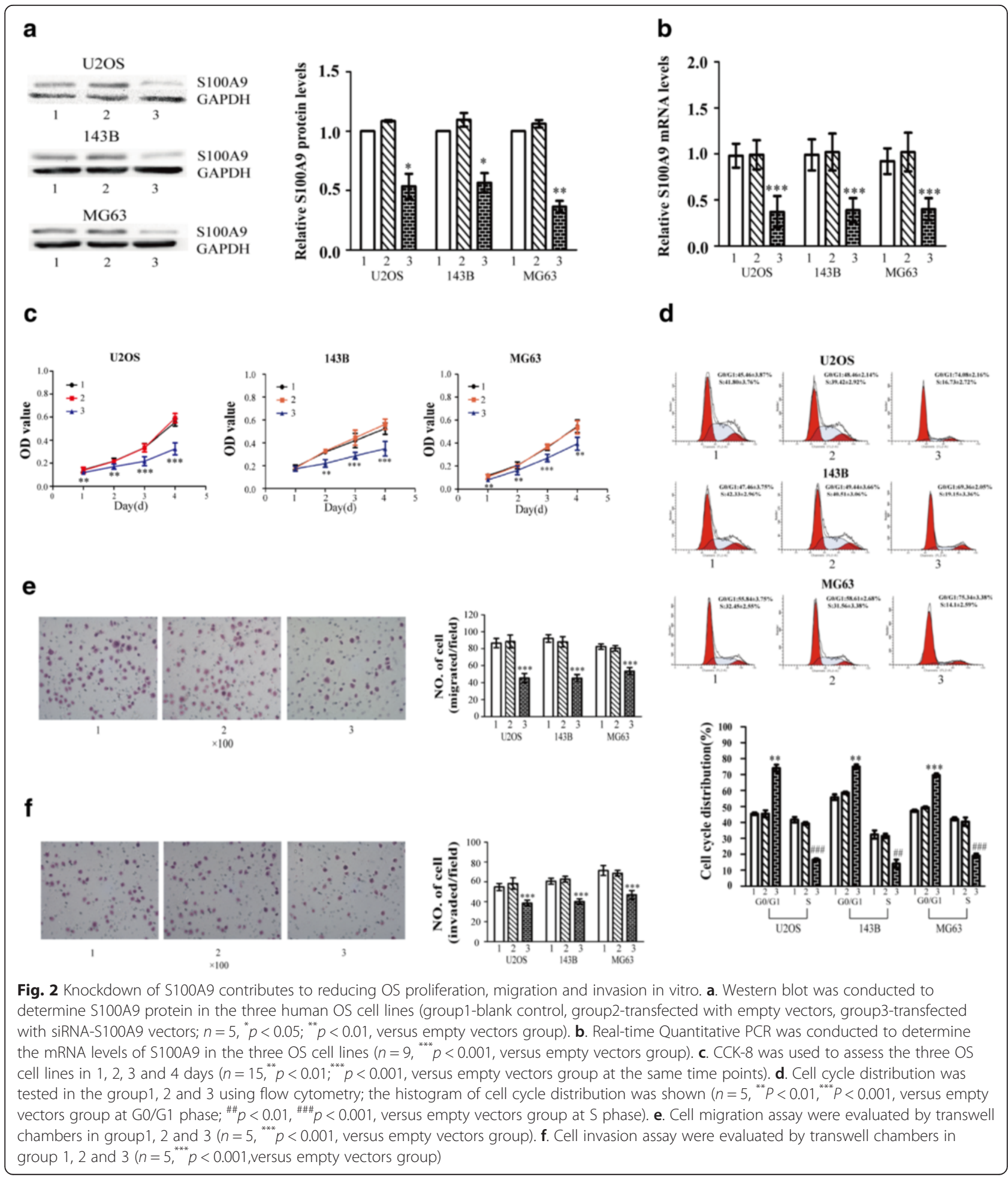


was shown in Fig. 2d. It was revealed that knockdown of S100A9 could contribute to accumulation of OS cells in G0/G1 phase in comparison with empty vectors groups and blank control groups (Fig. 2d). Next, we assessed the effects of S100A9 knockdown on migration and invasion capacity. The number of cells migrated across the polycarbonate membrane was also reduced after silence of S100A9 (Fig. 2e), while the invasion of tumor cells was significantly inhibited (Fig. 2f). The migration assay and invasion assay proved S100A9 posed a great influence on the metastasis in human OS cell lines.

\section{Knockdown of S100A9 gene inhibits OS growth in vivo}

Furthermore, we established the effects of S100A9 on OS growth in vivo using a xenograft model (Fig. 3a). OS cells treated with siRNA- S100A9 vectors groups or empty vectors groups were implanted in subcutaneous tissues of nude mice, and corresponding neoplasm volumes were measured every 7 days. Figure 3b showed that downregulation of S100A9 in OS cells significantly decreased tumor sizes, compared with empty vectors groups. The proliferating cell nuclear antigen (PCNA) and ki67 proliferation index for these solid tumor masses were calculated after 28 days implantation, the proliferation index of the tumors obtained from siRNA-S100A9 vectors groups was lower than that from the empty vectors groups (Fig. 3c).

\section{Reduced S100A9 down-regulates MAPK signaling and NF-KB signaling in OS cells}

To probe the molecular events after silence of S100A9 in OS cells, we tested the phosphorylation of MAPK and $\mathrm{NF}-\mathrm{KB}$ signaling pathways by western blot analysis and enzyme activity assay. Western blot analysis revealed that the protein levels of phospho-ERK1/2 MAPK, phospho-p50 NF- $\kappa$ B and phospho-p65 NF- $k B$ in siRNAS100A9 vectors groups were lower than those in empty vectors groups and blank control groups in OS cell lines (Fig. 4a). Enzyme activity assay also confirmed the above conclusions (Fig. 4b). However, the protein level and enzyme activity of phospho-p38 MAPK in siRNA-S100A9 vectors groups presented no substantial changes compared with the other two groups (Fig. 4a and b)

\section{Reduced S100A9 up-regulates the cell cycle-related proteins} p21 and p27 causing the inactivation of CDK2 and CDK4

The inhibition of cell-cycle progression at the G1 checkpoint by cell-cycle regulators p21 and p27 [25] became a considerably attractive mechanism for targeting cancers $[26,27]$. Thus, we wondered whether S100A9 modulated the expression of p21 and p27 as well. Western blot quantification revealed an increasing expression of p21 and p27 in siRNA-S100A9 vectors groups (Fig. 5a). In parallel, the enzyme activity assay of cyclin dependent kinase 2(CDK2) and cyclin dependent kinase 4(CDK4) were suppressed in the three OS cells transfected with siRNA-S100A9 (Fig. 5b).

\section{Discussions}

The recent accumulative studies have demonstrated that the S100 family members, notably S100A9, played a critical role in tumor development and progression due to their involvement in survival, growth and metastasis of tumor cells [28]. Nevertheless, little is known concerning the role of S100A9 in human osteosarcoma. In this study, it was the first report that S100A9 was considerably overexpressed in OS patient samples and its expression level in the OS cells was statistically correlated with neoplastic growth. PCNA and ki67 proliferation index would also support these conclusions. Reports showed that the two proteins (PCNA and ki67) have emerged in the S phase and participated in cell proliferation [29]. With the above information, we concluded that the expression level of S100A9 in OS cells could be an independent factor for the patients' prognosis. All these studies proved that S100A9 was involving in the OS progression.

S100A9, one member of the family of low-molecularweight intracellular EF-hand motif calcium-binding proteins, is abundantly expressed in cells of the myeloid lineage, including cytoplasmic proteins in neutrophils, macrophages at early-differentiation states and a smaller extent in monocytes [30]. S100A9 which shares a lot of similar characteristics with other S100 proteins locates on a cluster of human chromosome 1q21, where several chromosomal abnormalities have been found to be linked with neoplasia [31-33]. In our study, S100A9 independently promoted the tumor growth, migration and invasion in vitro. But in fact it may be not the only pathway in vivo, the cancer microenvironment might be a critical reason. The composition of tumor microenvironment is very complicated. Infiltrating inflammatory cells have been identified as one important componet. Inflammatory mediators induce the accumulation of myeloid cells, including myeloid-derived suppressor cells (MDSC). They have the potent immunesuppressive effects that could promote tumor growth by inhibiting T-cell-driven anti-tumor immune responses and support immune evasion through the release of reactive oxygen species (e.g. nitric oxide), cytokines, and arginase [34]. Over-expression of S100A9 could increase MDSC recruitment [35]. S100A9 knockout mice are better able to reject EL4 lymphomas compared to wild type mice for inhibiting the recruitment of MDSC [36]. Another example, $\mathrm{CD} 11 \mathrm{~b}(+) \mathrm{Gr} 1(+)$ cells are classical markers of murine MDSC which have been identified in tumorbearing mice [37, 38]. Mice lacking S100A9 have apparently reduced infiltration of $\mathrm{CD} 11 \mathrm{~b}(+) \mathrm{Gr} 1(+)$ cells within tumors and pre-metastatic organs showed lower tumor incidence, growth and migration [23]. It has been reported that S100A9 not only induce the accumulation of MDSC, 


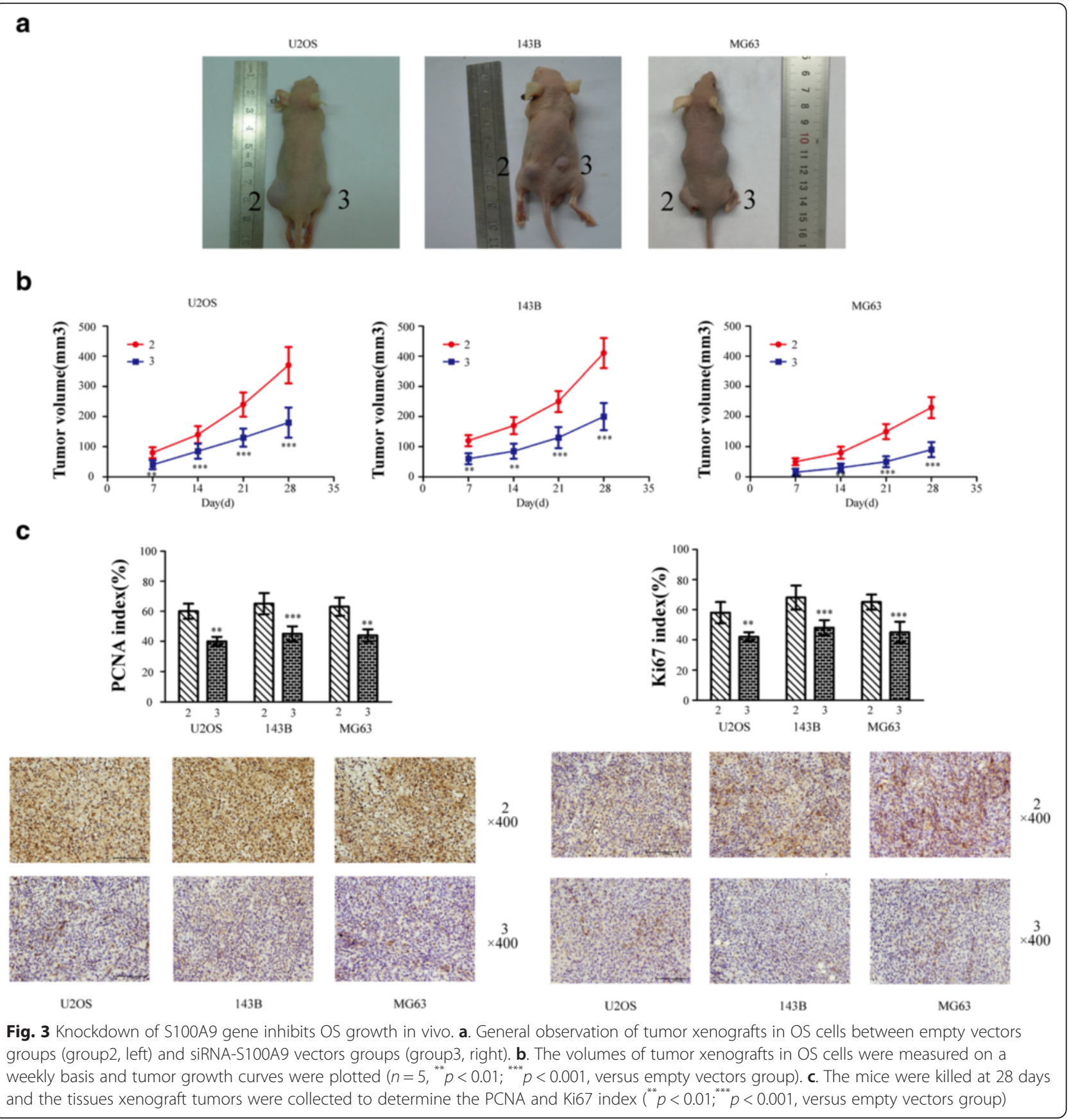

but it is also secreted by MDSC and tumor cells, and bind to cell surface receptors (such as RAGE) leading to MDSC migration [39]. So the autocrine feedback loop is created between S100A9 and MDSC that have significant influence on the inflammatory tumor environment.

In most cases, S100A9 is usually as a ligand. The main receptors for S100A9 are the receptor for advanced glycation mend-products (RAGE) and toll-like receptor 4 (TLR4) [40]. RAGE is a type I transmembrane protein, and a signaling receptor of the immunoglobulin superfamily.
Mounting studies have implicated that RAGE involved in many pathologies (diabetes, inflammation, neuronal degeneration and cancers) are regard as a receptor and effector of intracellular responses mediated by DAMPs [41, 42]. Tolllike receptor 4(TLR4) is one of the transmembrane receptors that enable cells of the innate immune system to mount inflammatory responses against pathogen [43]. S100A9 and serum amyloid A3(an important downstream molecule of S100A9) were bound to TLR4 [44]. RAGE and TLR4 are both implicated in S100A9-mediated 


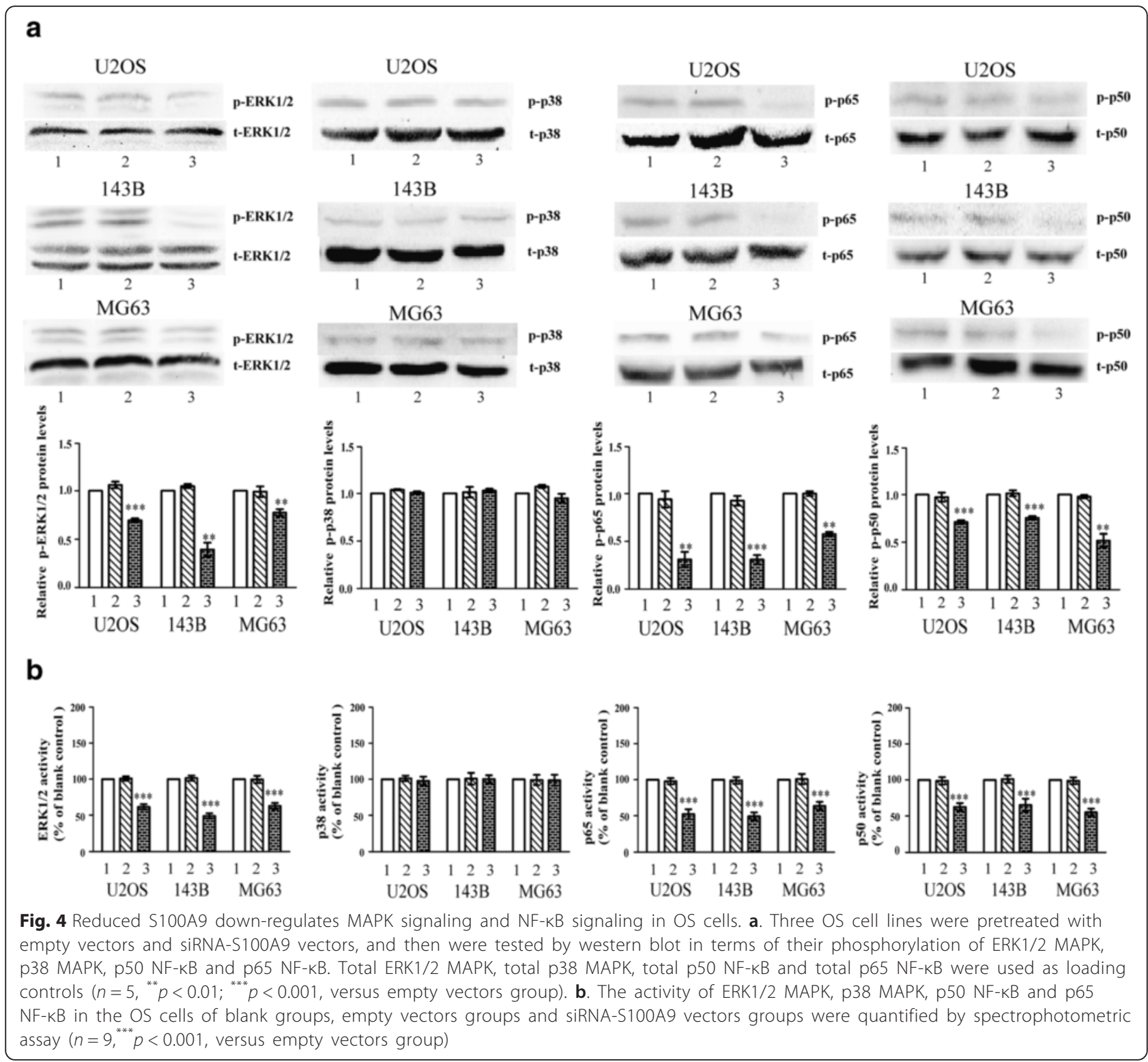

tumor-associated pathological effects. It has been reported that S100A9 could recruit additional MDSC into the tumor microenvironment by binding to RAGE [45] and S100A9 interaction with TLR4 is critical for tumor growth in lymphoma [46]. Besides RAGE and TLR4, extracellular matrix metalloproteinase inducer (EMMPRIN), known as CD147, has been found as a new receptor which specifically bound to S100A9 [47]. The carcinogenicity of EMMPRIN might be related to matrix metalloproteinases (MMPs) [48].

In some tumors, S100A9 mediates proliferative and invasive signals and enhances the MAPK or NF- $\mathrm{KB}$ signaling pathway [49]. The aberrant activations of MAPK and NF- $\mathrm{KB}$ signaling pathways both have critical effects on tumor growth and migration [50-53], which was found in OS cells according to previous studies [54]. Although some components about the downstream of MAPK or NF-kB signaling pathways have been discussed, there were many disputes which genes could control the activity of two signaling pathways. According to our reports, we observed that the suppression of S100A9 caused decreases in the phosphorylation activity of ERK1/2, NF-кB-p50, NF-kB-p65 as well as no detectable phosphorylation of MAPK-p38. This indicated that S100A9 might mediate the tumor progression in OS cells by promoting cellular migration and invasion, which was linked to MAPK and NF- $\mathrm{kB}$ signaling pathways. Interestingly, our conclusion was consistent with 
a
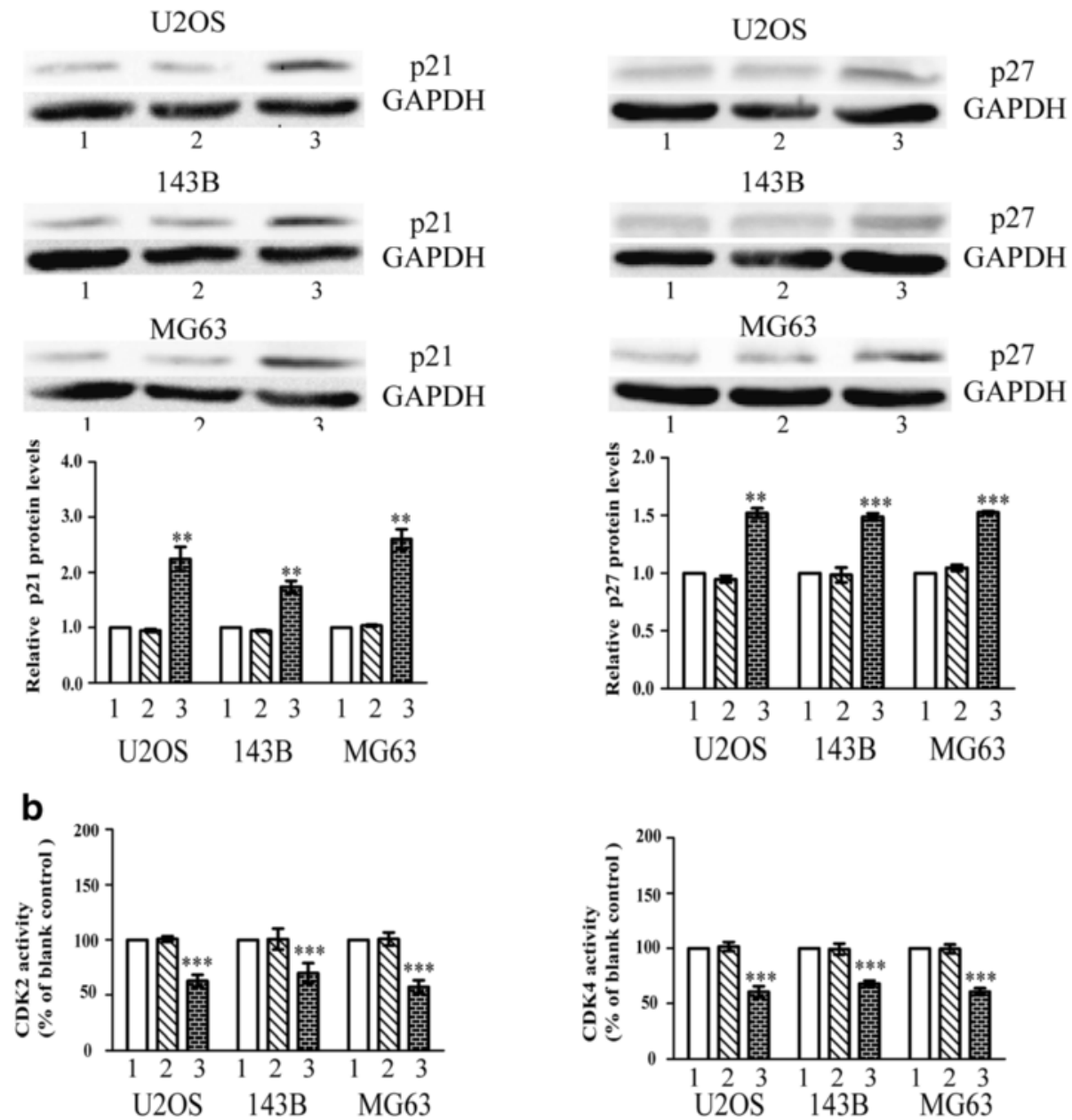

Fig. 5 Reduced S100A9 up-regulates the cell cycle-related proteins p21 and p27 causing the inactivation of CDK2 and CDK4. a. Three OS cell lines were treated with empty vectors and siRNA-S100A9 vectors, and then were tested by western blot in terms of p21 and p27. GAPDH was used as loading control ( $n=5,{ }^{* *} p<0.01 ;{ }^{* * *} p<0.001$, versus empty vectors group). b. The activity of CDK2 and CDK4 in OS cells of blank control groups, empty vectors groups and siRNA-S100A9 vectors groups were quantified by spectrophotometric assay $(n=9, p<0.001$, versus empty vectors group)

the findings that S100A9 activated phosphorylation of ERK1/2 but not phosphorylation of MAPK-p38 signaling pathway [23]. Instead, it has been found that S100A9 increased phosphorylation of MAPK-p38, but inhibited phosphorylation of ERK1/2 in gastric cancers [55]. Therefore, the actions of S100A9 through MAPK signals could be depend on the different types of cancer cells. The MAPK signaling pathways might be act as a various role in different cancerous tumors.

\section{Conclusions}

To sum up, we have evidenced the involvement of S100A9 in OS pathology, showing that knockdown of S100A9 can reduce OS development through inactivation of MAPK and NF- $\mathrm{kB}$ signaling pathways. Therefore, we prone to put S100A9 as a significant parameter for predicting human osteosarcoma patients' prognosis and S100A9 might be used as a potential target for cytokine therapy.

\section{Availability of data and materials}

The datasets supporting the conclusions of this article are available in the repository.

The datasets supporting the conclusions of this article are included within the article and its Additional files 1, 2,3 and 4 .

\section{Additional files}

Additional file 1: FigureS1 The knockdown of S100A9 had no effect on the cell apoptosis, RAGE or TLR4. A. The apoptosis was tested after knockdown of S100A9 $(n=3)$. A histogram about the sum of the upper right quadrant(Q2) and the lower right quadrant(Q3) was shown in

Supplement fig.1A. Q2 represents late apoptotic cells, Q3 represents early 
apoptotic cells. B. The protein levels of RAGE and TLR4 were tested by western blot in three OS cell lines (group1-blank control, group2transfected with empty vectors, group3-transfected with siRNA-S100A9 vectors; $n=3$ ). (TIFF $5193 \mathrm{~kb}$ )

Additional file 2: FigureS2 The up-regulation of S100A9 enhanced osteosarcoma proliferation, migration and invasion.A.The protein levels of S100A9 were tested by western blot in the three OS cell lines (group1blank control, group2-transfected with empty vectors, group3-transfected with $\mathrm{S100A9}$ vectors; $n=3$, ${ }^{* * *} P<0.001$, versus empty vectors group). $B$. The mRNA levels of S100A9 were tested by real-time Quantitative PCR in the three OS cell lines ( $n=9$, ${ }^{* *} P<0.001$, versus empty vectors group). C. CCK-8 was used to assess the three OS cell lines in 1, 2, 3 and 4 days $\left(n=15,{ }^{*} p<0.05,{ }^{* *} \mathrm{P}<0.01 ;{ }^{* * *} \mathrm{P}<0.001\right.$, versus empty vectors group at the same time points). D. Cell cycle distribution was tested in the group1, 2 and 3 using flow cytometry; the histogram of cell cycle distribution was shown $\left(n=3\right.$, ${ }^{* *} P<0.01$, versus empty vectors group at G0/G1 phase; \#\#P $<0.01$, versus empty vectors group at $\mathrm{S}$ phase). E. The histogram of cell migration assay were evaluated by transwell chambers in group 1,2 and $3\left(n=5_{1}{ }^{* * *} P<0.001\right.$, versus empty vectors group). $F$. The histogram ofcell invasion assay were evaluated by transwell chambers in group 1,2 and 3 ( $n=5,{ }^{* * *} P<0.001$, versus empty vectors group).(TIFF $10616 \mathrm{~kb}$ )

Additional file 3: FigureS3 A.The mRNA levels of S100A9 were tested by real-time Quantitative PCR in osteosarcoma tissues andnormal bone tissues $\left(n=3,{ }^{* *} p<0.01,{ }^{* * *} p<0.001\right.$, versus normal bone group; \#\#p $<$ 0.001 , versus OS Grade III). B.The protein levels of S100A9 were tested in three fresh osteosarcoma tissues and normal bone tissue. Tumor 1 and tumor 2 belonged to grade I, tumor 3 belonged to grade III.(TIFF 1805 $\mathrm{kb})$

Additional file 4: FigureS4 A.The photos of immunofluorescence for observing in the OS cell lines were shown. B. CCK-8 was used toassess the three OS cell lines in 1, 2, 3 and 4 days ( $n=15$, group 1-blank control, group2-transfected with empty vectors, group3-transfected with siRNATLR4 vectors). C. CCK-8 was used to assess the three OS cell lines in 1, 2, 3 and 4 days (group1-blank control, group2-transfected with empty vectors, group3- 10.1186/s12885-016-2294-1 transfected with siRNA-EMMPRIN vectors; $n=15,{ }^{* * P}<0.01 ;{ }^{* * *} \mathrm{P}<0.001$ )(TIFF $4998 \mathrm{~kb}$ )

\section{Abbreviations}

CCK8: cell counting kit-8; CDK2: cyclin dependent kinase 2; CDK4: cyclin dependent kinase 4; DMEM: Dulbecco's modified Eagle's medium; EMMPRIN: extracellular matrix metalloproteinase inducer; FBS: fetal bovine serum; GAPDH: glyceraldehydes-3-phosphate dehydrogenase; MAPK: mitogen-activated protein kinase; MDSC: myeloid-derived suppressor cells; NF-kB: nuclear factor-KB; OS: osteosarcoma; PCNA: proliferating cell nuclear antigen; PCR: polymerase chain reaction; PMSF: phenylmethanesulfonyl fluoride; PVDF: polyvinylidene difluoride; RAGE: receptor for advanced glycation mend-products (RAGE); TLR4: toll-like receptor 4.

\section{Competing interests}

The authors declare that they have no competing interests.

\section{Authors' contributions}

SC conceived and performed the experiments. $\mathrm{XZ}, \mathrm{YJ}$ and $\mathrm{NH}$ were involved in cell experiments. $\mathrm{NH}, \mathrm{QHQ}$ and $\mathrm{DMJ}$ were involved in nude mice studies. QHQ contributed to analysis the data. SC drafted the manuscript. DMJ participated in design and coordination. All authors read and approved the final manuscript.

\section{Acknowledgments}

We would like to thank Ms MingDan Tan, Ms Yanling Lian and Ms Fenling He for technical assistance about tissue microarrays and IHC.

\section{Author details}

${ }^{1}$ Department of Orthopaedics, The First Affiliated Hospital of Chongqing Medical University, Chongqing, PR China. '2Department of Nephrology, The First Affiliated Hospital of Chongqing Medical University, Chongqing, PR China. ${ }^{3}$ Department of Neurosurgery, The Second Affiliated Hospital of Chongqing Medical University, Chongqing, PR China. ${ }^{4}$ Institute of Life Sciences,Chongqing Medical University, Chongqing, PR China. ${ }^{5}$ Department of Orthodontics, State Key Laboratory of Oral Diseases, West China Hospital of Stomatology, WestChina School of Stomatology, Sichuan University, Chongqing, PR China.

Received: 13 June 2015 Accepted: 23 March 2016

Published online: 28 March 2016

\section{References}

1. Pierron G, Tirode F, Lucchesi C, Reynaud S, Ballet S, Cohen-Gogo S, et al. A new subtype of bone sarcoma defined by BCOR-CCNB3 gene fusion. Nat Genet. 2012:44:461-6.

2. Ottaviani G, Jaffe N. The epidemiology of osteosarcoma. Cancer Treat Res. 2009;152:3-13.

3. Kager L, Zoubek A, Kastner U, Kempf-Bielack B, Potratz J, Kotz R, et al. Skip metastases in osteosarcoma: experience of the Cooperative Osteosarcoma Study Group. J Clin Oncol. 2006;24:1535-41.

4. Siegel HJ, Pressey JG. Current concepts on the surgical and medical managementof osteosarcoma. Expert Rev Anticancer Ther. 2008;8:1257-69.

5. Ferrari S, Palmerini E. Adjuvant and neoadjuvant combination chemotherapy for osteogenic sarcoma. Curr Opin Oncol. 2007;19:341-4.

6. Hattinger CM, Pasello M, Ferrari S, Picci P, Serra M. Emerging drugs for highgrade osteosarcoma. Expert Opin Emerg Drugs. 2010;15:615-34.

7. Huang J, Ni J, Liu K, Yu Y, Xie M, Kang R, et al. HMGB1 promotes drug resistance in osteosarcoma. Cancer Res. 2012;72:230-8.

8. Srikrishna G. S100A8 and S100A9: new insights into their roles in malignancy. Innate Immun. 2012:4:31-40.

9. Roth J, Vogl T, Sorg C, Sunderkotter C. Phagocyte-specific S100 proteins: a novel group of proinflammatory molecules. Trends Immunol. 2003:24:155-8.

10. Kerkhoff C, Nacken W, Benedyk M, Dagher MC, Sopalla C, Doussiere J. The arachidonic acid-binding protein S100A8/A9 promotes NADPH oxidase activation by interaction with p67phox and Rac-2. FASEB J. 2005;19:467-9.

11. Vogl T, Ludwig S, Goebeler M, Strey A, Thorey IS, Reichelt R, et al. MRP8 and MRP14 control microtubule reorganization during transendothelial migration of phagocytes. Blood. 2004;104:4260-8.

12. Cornish CJ, Devery JM, Poronnik P, Lackmann M, Cook DI, Geczy CL. S100 protein CP-10 stimulates myeloid cell chemotaxis without activation. J Cell Physiol. 1996;166:427-37.

13. Roth J, Goebeler M, Sorg C. S100A8 and S100A9 in inflammatory diseases. Lancet. 2001;357:1041.

14. Gebhardt C, Nemeth J, Angel P. Hess J.S100A8 and S100A9 in inflammation and cancer. Biochem Pharmacol. 2006;72:1622-31.

15. Porta C, Larghi P, Rimoldi M, Totaro MG, Allavena P, Mantovani A, et al. Cellular and molecular pathways linking inflammation and cancer. Immunobiology. 2009; 214:761-77.

16. Salama I, Malone PS, Mihaimeed F, Jones JL. A review of the S100 proteins in cancer. Eur J Surg Oncol. 2008;34:357-64.

17. Luo A, Kong J, Hu G, Liew CC, Xiong M, Wang X, et al. Discovery of $\mathrm{C} a 2+$-relevant and differentiation associated genes downregulated in esophageal squamous cell carcinoma using cDNA microarray. Oncogene. 2004:23:1291-9.

18. Avruch J. MAP kinase pathways: the first twenty years. Biochim Biophys Acta. 2007;1773:1150-60.

19. Chang L, Karin M. Mammalian MAP kinase signalling cascades. Nature. 2001; 410:37-40.

20. Manning G, Whyte DB, Martinez R, Hunter T, Sudarsanam S. The protein kinase complement of the human genome. Science. 2002;298:1912-34.

21. Dhawan P, Richmond A. A novel NF-KB-inducing kinase-MAPK signaling pathway up-regulates NF-kB activity in melanoma cells. J Biol Chem. 2002; 277:7920-8

22. Ghavami S, Rashedi I, Dattilo BM, Eshraghi M, Chazin WJ, Hashemi M, et al. S100A8/A9 at low concentration promotes tumor cell growthvia RAGE ligation and MAP kinase-dependent pathway. J Leukoc Biol. 2008; 83:1484-92.

23. Ichikawa M, Williams R, Wang L, Vogl T, Srikrishna G. S100A8/A9 activate key genes and pathways in colon tumor progression. Mol Cancer Res. 2011;9: 133-48.

24. Wen K, Fu Z, Wu X, Feng J, Chen W, Qian J. Oct-4 is required for an antiapoptotic behavior of chemoresistant colorectal cancer cells enriched for cancer stem cells: effects associated with STAT3/Survivin. Cancer Lett. 2012;333:56-65. 
25. Vermeulen K, Van Bockstaele DR, Berneman ZN. The cell cycle: a review of regulation, deregulation and therapeutic targets in cancer. Cell Prolif. 2003; 36:131-49.

26. Borriello A, Bencivenga D, Criscuolo M, Caldarelli I, CucciollaV TA, et al. Targeting p27Kip1 protein: its relevance in the therapy of human cancer. Expert Opin Ther Targets. 2011;15:677-93.

27. Abbas T, Dutta A. p21 in cancer: intricate networks and multiple activities. Nat Rev Cancer. 2009:9:400-14

28. Markowitz J, Carson 3rd WE. Review of S100A9 biology and its role in cancer. Biochim Biophys Acta. 1835;2013:100-9.

29. Hafeez BB, Siddiqui IA, Asim M, Malik A, Afaq F, Adhami VM, et al. A dietary anthocyanidin delphinidin induces apoptosis of human prostate cancer PC3 cells in vitro and in vivo: involvement of nuclear factorkappaB signaling. Cancer Res. 2008;68:8564-72.

30. Chazin WJ. Relating form and function of EF-hand calcium binding proteins. Acc Chem Res. 2011:44:171-9.

31. Goeze A, Schluns K, Wolf G, Thasler Z, Petersen S, Petersen I. Chromosomal imbalances of primary and metastatic lung adenocarcinomas. J Pathol. 2002;196:8-16

32. Koon N, Zaika A, Moskaluk CA, Frierson HF, Knuutila S, Powell SM, et al. Clustering of molecular alterations in gastroesophageal carcinomas. Neoplasia. 2004:6:143-9.

33. Moinzadeh P, Breuhahn K, Stützer H, Schirmacher P. Chromosome alterations in uman hepatocellular carcinomas correlate with aetiology and histological rade-results of an explorative CGH meta-analysis. $\mathrm{Br} J$ Cancer. 2005;92:935-41.

34. Ostrand-Rosenberg S. Myeloid-derived suppressor cells: more mechanisms for inhibiting antitumor immunity. Cancer Immunol Immunother. 2010;59: 1593-600.

35. Cheng P, Corzo CA, Luetteke N, Yu B, Nagaraj S, Bui MM, et al. Inhibition of dendritic cell differentiation and accumulation of myeloid-derived suppressor cells in cancer is regulated by S100A9 protein. J Exp Med. 2008:205:2235-49.

36. Ko JS, Bukowski RM, Fincke JH. Myeloid-derived suppressor cells: a novel therapeutic target. Curr Oncol Rep. 2009;11:87-93.

37. Connolly MK, Mallen-St Clair J, Bedrosian AS, Malhotra A, Vera V, Ibrahim J, et al. Distinct populations of metastases-enabling myeloid cells expand in the liver of mice harboring invasive and preinvasive intra-abdominal tumor. J Leukoc Biol. 2010;87:713-25.

38. Yan HH, Pickup M, Pang Y, Gorska AE, Li Z, Chytil A, et al. Gr-1 + CD11b + myeloid cells tip the balance of immune protection to tumor promotion in the premetastatic lung. Cancer Res. 2010;70:6139-49.

39. Sinha P, Okoro C, Foell D, Freeze HH, Ostrand-Rosenberg S, Srikrishna G. Proinflammatory $\mathrm{S} 100$ proteins regulate the accumulation of myeloid-derived suppressor cells. J Immunol. 2008;181:4666-75.

40. Gao H, Zhang X, Zheng Y, Peng L, Hou J, Meng H. S100A9- induced release of interleukin (IL)-6 and IL-8 through toll-like receptor 4 (TLR4) in human periodontal ligament cells. Mol Immunol. 2015;67:223-32.

41. Logsdon CD, Fuentes MK, Huang EH, Arumugam T. RAGE and RAGE ligands in cancer. Curr Mol Med. 2007;7:777-89.

42. Yan SF, Ramasamy R, Schmidt AM. Receptor for AGE (RAGE) and its ligands-cast into leading roles in diabetes and the inflammatory response. J Mol Med. 2009; 87:235-47.

43. Takeda K, Akira S. Toll-like receptors. Curr Protoc Immunol. 2007:Unit 14:12.

44. Källberg E, Vogl T, Liberg D, Olsson A, Björk P, Wikström P, et al. S100A9 interaction with TLR4 promotes tumor growth. PLoS One. 2012;7, e34207.

45. Turovskaya O, Foell D, Sinha P, Vogl T, Newlin R, Nayak J, et al. RAGE, carboxylated glycans and S100A8/A9 play essential roles in colitis-associated carcinogenesis. Carcinogenesis. 2008;29:2035-43.

46. Leanderson T, Ivars F. S100A9 and tumor growth. Oncoimmunology. 2012;1:1404-5

47. Hibino T, Sakaguchi M, Miyamoto S, Yamamoto M, Motoyama A, Hosoi J, et al. S100A9 is a novel ligand of EMMPRIN that promotes melanoma metastasis. Cancer Res. 2013:73:172-83.

48. Gabison EE, Hoang-Xuan T, Mauviel A, Menashi S. EMMPRIN/CD147, an MMP modulator in cancer, development and tissue repair. Biochimie. 2005; 87:361-8.

49. Simard JC, Girard D, Tessier PA. Induction of neutrophil degranulation by S100A9 via a MAPK-dependent mechanism. J Leukoc Biol. 2010;87: 905-14.

50. Ghavami S, Chitayat S, Hashemi M, Eshraghi M, Chazin WJ, Halayko AJ, et al. S100A8/A9: a Janus-faced molecule in cancer therapy and tumorgenesis. Eur J Pharmacol. 2009;625:73-83.
51. Platanias LC. Map kinase signaling pathways and hematologic malignancies. Blood. 2003:101:4667-79.

52. Fang JY, Richardson BC. The MAPK signalling pathways and colorectal cancer. Lancet Oncol. 2005;6:322-7.

53. Kraunz KS, Nelson HH, Liu M, Wiencke JK, Kelsey KT. Interaction between the bone morphogenetic proteins and Ras/MAP-kinase signalling pathways in lung cancer. Br J Cancer. 2005;93:949-52.

54. Shimo T, Matsumura S, Ibaragi S, Isowa S, Kishimoto K, Mese H, et al. Specific inhibitor of MEK-mediated cross-talk between ERK and p38 MAPK during differentiation of human osteosarcoma cells. J Cell Commun Signal. 2007;1:103-11.

55. Kwon CH, Moon HJ, Park HJ, Choi JH, Park do Y. S100A8 and S100A9 promotes invasion and migration through p38 mitogen-activated protein kinasedependent NF-kB activation in gastric cancer cells. Mol Cells. 2013;35:226-34

\section{Submit your next manuscript to BioMed Central and we will help you at every step:}

- We accept pre-submission inquiries

- Our selector tool helps you to find the most relevant journal

- We provide round the clock customer support

- Convenient online submission

- Thorough peer review

- Inclusion in PubMed and all major indexing services

- Maximum visibility for your research

Submit your manuscript at www.biomedcentral.com/submit
C) BioMed Central 